(PELC-LC distant from PELC-ST) and the Control Group-LC (PELCLC close to PELC-ST). In the retrospective study a quality interval is defined, with upper limit equal to PELC-ST, enabling to sort the lines in the groups. In the prospective study, the "Management experimentation" produces the lines of the Control Group-LC. The "Aftercare system" monitors quality of care that is coming. A "Selfreferred health" explores the relationship between PELC-LC and selfperceptions of the healthcare consumer (PELC-HC).

Result The Method PELC allows local and multicenter studies in the investigation of clinical-social-organizational factors that act on the lines of care.

Conclusions The Method PELC leaves open to discussion a new line of research to the lines of care.

\section{P1-300 DISEASE PATTERN AND HEALTH-SEEKING BEHAVIOUR IN A RURAL AREA OF BANGLADESH}

doi:10.1136/jech.2011.142976e.92

M Rahman, * M Islam, R Islam, G Sadhya, A Latif. Faridpur Medical College, Faridpur, Bangladesh

Knowledge about existing disease pattern and health seeking behaviour is essential to provide need-based healthcare delivery and to make the healthcare system more pro-poor. A community-based cross sectional study was conducted among 493 systematically selected households to determine the prevailing disease pattern and health seeking behaviour in rural Bangladesh. More than half of the respondents gave history of illness of family members during the preceding 15 days. Fever, gastrointestinal and respiratory diseases were the most reported complaints. Overall, there were no discernible differences in the likelihood of seeking traditional or any kind of care considering socio-demographic variables and prevailing disease types. Occupation of household head as day labour or in agriculture and suffering from gastrointestinal diseases positively predicted use of para-professionals. Use of un-qualified allopaths was negatively predicted by the male gender or literacy of the household head and presence of gastrointestinal, respiratory and other types of diseases and positively predicted by occupation of the household head in agricultural field or as day labour. Use of qualified allopaths was positively predicted by respiratory, skin/eye/ENT and other types of diseases and also by standard of living and relationship of the respondents with household head and negatively predicted by agricultural or day labour work of the household head. Existence of several distinct therapeutic systems in a single cultural setting was found in the study area. It is important to develop a need based healthcare delivery system and actions should be taken to improve overall scenario of health system of rural Bangladesh.

\section{P1-301 A COMPARISON OF TWO METHODS TO ESTIMATE THE CANCER INCIDENCE AND MORTALITY BURDEN IN CHINA IN 2005}

doi:10.1136/jech.2011.142976e.93

\begin{abstract}
${ }^{1} \mathrm{~J} S$ Ren, ${ }^{*}{ }^{2} \mathrm{~W} O \mathrm{C}$ Chen, ${ }^{1} \mathrm{H}$ R Shin, ${ }^{1} \mathrm{~J}$ Ferlay, ${ }^{3} \mathrm{~K}$ Saika, ${ }^{2} \mathrm{~S}$ W Zhang, ${ }^{1} \mathrm{~F}$ Bray. ${ }^{1}$ International Agency for Research on Cancer, Lyon, France; ${ }^{2}$ National Office for Cancer Prevention and Control, Beijing, China; ${ }^{3}$ National Cancer Center, Tokyo, Japan
\end{abstract}

Introduction Knowledge of the cancer profile is an important step in planning rational cancer control programs and the evaluation of their impact. Due to rapid changes in cancer incidence over in China, national surveys may be insufficiently timely to provide adequate descriptions of the national burden.

Methods To evaluate the utility of cancer registries in describing the national cancer profile, this study compared two methods of esti- mating national cancer-specific incidence and mortality in China 2005, with estimates based on the Third National Death Survey (method I) compared with those based on registry material (method II).

Results A total of 2.6 million cancer cases and 1.8 million cancer deaths were estimated by method I, as compared to 2.8 million cancer cases and 1.9 million cancer deaths using method II.

Conclusion The higher level of burden using the latter method in part may be due to a sizable differential in the magnitude of incidence rates across registries for certain cancer sites. Most cancer registries were located in relatively more developed urban areas, or rural areas associated with higher risk for certain cancers. There are substantial differences in the cancer profile between urban and rural communities in China, and there may be concerns regarding the national representativeness of the data aggregated from this set of cancer registries. Timely and reliable estimation of cancer can only be realised if accurate information is available from cancer registries comprising representative samples of the country.

\section{P1-302 POSITIVE ASSOCIATION BETWEEN TRAFFIC-RELATED AIR POLLUTION AND SOCIOECONOMIC STATUS IN A MEGACITY OF A DEVELOPING COUNTRY}

doi:10.1136/jech.2011.142976e.94

\section{A Ribeiro, ${ }^{*}$ A Nardocci. University of São Paulo, São Paulo, Brazil}

Introduction Most studies have shown that populations with lower socioeconomic status tend to experience higher levels of exposure to environmental air pollutants. We investigated the association between neighbourhood socioeconomic status and traffic related air pollution in São Paulo.

Methods We calculated total traffic density and traffic density for vehicles powered by gasoline and diesel, from traffic counts data, for 4964 geographical units with a population of 20 or more inhabitants, formed by a grid of 500 by 500 metres. The Human Development Index (HDI) was used as a socio-economic indicator and obtained for each of these geographic units. We analysed the association through logistic regression models for traffic density categories.

Results The neighbourhood socio-economic status was positively associated with all measures of traffic density with clear doseresponse gradient. The category with the highest HDI presented Rate ratios of 10.2 (95\% CI 7 to 14.9), 9.6 (95\% CI 6.6 to 13.9) and 17.5 (95\% CI 10.8 to 28.4), respectively, for total, gasoline and diesel vehicles traffic density.

Conclusion Our analysis suggests that richer areas are more exposed to traffic related air pollution. The greatest socioeconomic difference in exposure was found for diesel exhaust. In search of a more equitable solution of this environmental problem, investigations are warranted in megacities of developing countries about how the development of the road network and vehicle traffic relates to sites historically occupied by different social classes.

\section{P1-303 INEQUALITIES IN SILICA EXPOSURE: A STUDY USING JOB EXPOSURE MATRIX}

doi:10.1136/jech.2011.142976e.95

${ }^{1} \mathrm{~F}$ Ribeiro, ${ }^{*}{ }^{2} \mathrm{~B}$ Bernales, ${ }^{2} \mathrm{~J}$ Alcaíno, ${ }^{2} \mathrm{G}$ Contreras, ${ }^{3} \mathrm{~W}$ Chumbe, ${ }^{3} \mathrm{~J}$ Olivas, ${ }^{4} \mathrm{~J}$ Almonacid, ${ }^{5} \mathrm{~F}$ González. ${ }^{1}$ Rio de Janeiro State University, Rio de Janeiro, Brazil; ${ }^{2}$ Public Health Institute, Ministry of Health, Santiago, Chile; ${ }^{3}$ Digesa/Ministry of Health, Lima, Peru; ${ }^{4}$ Ministry of Social Protection, Bogotá, Colombia; ${ }^{5}$ Western University Lisandro Alvarado, Barquisimeto, Venezuela

Silicosis still persists as a worldwide problem and becomes a major problem for public health. Since 1995 the ILO/WHO established 
Global Program for the Elimination of Silicosis. In 2006, at the second international meeting of International Plan for Americas, a proposal to build a map of exposure situation based on a Job of Potential Exposure Matrix (JPEM) to silica as a surveillance methodology was made.

Objectives Estimate the numbers of workers exposed to silica in Brazil, Chile, Venezuela, Peru and Colombia.

Methods A JPEM developed in Brazil and matched with the study in Chile, according to the conception of CAREX database, was applied to workers in Chile, Venezuela, Peru and Colombia.

Results The percentages of workers exposed to crystalline silica were: Brazil (5.6\%), Chile (5.4\%), Peru (4.9\%), Venezuela (5.2\%) and Colombia $(6.0 \%)$. When compare to the percentage of workers exposed in Finland (3.8\%), Spain (3.3\%), Germany (2.9\%) Great Britain $(2.6 \%)$ and Italy $(1.6 \%)$, these data shows the relevance of silica dust exposure in the countries with economies based on polluting and health damaging technologies. Historically, this inequality was given by the transfer of obsolete technology and harmful work activities.

Conclusion Traditional surveillance, based only on the identification of cases, does not identify this historic process. Thus, job-exposure matrices are a potentially valuable addition to epidemiologic research methods. If applied judiciously, may contribute to etiologic research and to the identification and control of workplace exposures.

\section{P1-304 ASSOCIATION BETWEEN QUALITY OF LIFE AND NUTRITION STATUS OF OLDER ADULTS IN A MEDIUM- SIZED CITY IN SÃO PAULO STATE, BRAZIL}

doi:10.1136/jech.2011.142976e.96

${ }^{1} \mathrm{~L}$ B de Souza, ${ }^{1} \mathrm{~J}$ E Corrente.* ${ }^{1}$ Graduate Program in Collective Health, Botucatu School of Medicine, UNESP, Botucatu, São Paulo, Brazil; ${ }^{2}$ Department of Biostatistics, Biosciences Institute, UNESP, Botucatu, São Paulo, Brazil

Introduction In the last few decades, population growth patterns have shown high figures for older adults. Accentuated increase in the number of older individuals, particularly in developed countries, has brought consequences to society, and in order to face such challenge, it is necessary to identify the determinant causes of older persons' present health and life conditions.

Objective This study aimed at evaluating the existence of an association between quality of life and nutritional status in a sample of older residents in the city of Botucatu - São Paulo, Brazil.

Methodology It was an epidemiological, cross-sectional, populationbased study on individuals aged 60 years or older. A home interview was conducted with 96 elders. Their anthropometric measures were obtained and a Flanagan Quality of Life Scale (FOOLS) was applied.

Results The older individuals' mean age individuals was $74.1 \pm 7$ years. Most of them were females (60\%), poorly educated, married $(62.11 \%)$ and retired (84.21\%). According to FOOLS, $72.62 \%$ reported to be satisfied about their quality of life. As to nutritional status, it was found that $41 \%$ of the participants were overweight. Anthropometric measurements reduced as age advanced, although such reduction was not always significant. No significant association was observed between anthropometric measurements or nutritional status and quality of life.

Conclusions Although the majority of the older people reported to have good quality of life, obesity is still a factor of concern at this age range, and nutritional intervention programs as well as incentive to healthy diets should be recommended. P1-305 ROLE OF PROXIMAL AND DISTAL DETERMINANTS IN HAND
WASHING AND WATER TREATMENT PRACTICES IN SLUMS OF INDIA

doi:10.1136/jech.2011.142976e.97

Dr Ritvik, ${ }^{*}$ R A Krishnan, S Kapoor, C Pandav. All India institute of medical sciences, New Delhi, India

Introduction The determinants of health and disease can be classified as proximal and distal depending on their position in the causal pathway. This study attempts find out whether behaviour change communication interventions targeted at the proximal determinants (knowledge and infrastructure) of handwashing and water treatment change the relative importance of distal socio-economic status determinants.

Methods The analysis uses data from an evaluation of a Safe Water System intervention in urban slums of Haridwar and Dehradun districts of Uttarakhand, India. As a part of evaluation, two independent surveys were conducted in the SWS intervention area in $2004(n=1125)$ and $2005(n=1128)$. Analysis was based on framework of hierarchical modelling. Logistic regression was applied and the change in "population attributable fraction" (PAF) from baseline to endline models was calculated for arriving at the relative importance of the determinants.

Results At baseline, distal determinants were important for water treatment. Introduction of software variables to the model resulted in decline in the PAF of distal determinants from $89 \%$ to $74 \%$. At endline, the importance of distal determinants was further reduced (PAF of 23\%). For handwashing at baseline, the distal variables were less important for handwashing (PAF of 36\%). After intervention, there was smaller decline in their importance (PAF of $22.7 \%$ ). Proximal determinants assumed importance only after intervention. The models in the study could only partially explain the variance in two behaviours under study.

Conclusions Behaviour change communication interventions can help overcome influence of low socio-economic status or illiteracy by changing proximal determinants.

\section{P1-306 THE INFLUENCE OF CHILDHOOD DEVELOPMENTAL PLASTICITY AND SOCIOECONOMIC CIRCUMSTANCES ON ADULT HEALTH BIOMARKERS: LONGITUDINAL EVIDENCE FROM THE WEST OF SCOTLAND TWENTY-07 STUDY}

doi:10.1136/jech.2011.142976e.98

T Robertson, ${ }^{*}$ M Benzeval. Medical Research Council, Social \& Public Health Sciences Unit, Glasgow, UK

Physical development in early life adapts to environmental circumstances through developmental plasticity. Despite short-term gains, altered developmental trajectories can have long-term health consequences. This study investigates the individual and combined associations of childhood socioeconomic circumstances and developmental plasticity with adult health biomarkers. Respondents from the West of Scotland Twenty-07 Study were followed from ages 15 to 35 , with biomarkers sampled at 35 $(n=736)$. Social class mobility from birth to 15 categories were stable non-manual, stable manual, upwardly mobile or downwardly mobile. Developmental categories, based on birthweight and height at 15 tertiles, were stable (eg, average birthweight and height), compensatory (eg, low birthweight, tall height) or limited (eg, large birthweight, short height). Sex-specific GLMs including developmental and socioeconomic categories (separate and combined models) were analysed against Forced Expiratory Volume in $1 \mathrm{~s}$ 